\title{
Window of opportunity
}

\section{Time is running out to tackle climate change - it is not too late, but the next 10-15years will be critical.}

Peruvian President Ollanta Humala recently called for the "greatest alliance the world has ever seen" to tackle climate change and its impacts. This month his nation hosts, in Lima, the 20th Conference of the Parties (COP20) of the United Nations Framework Convention on Climate Change. Many see the meeting as a critical stepping stone on the path towards achieving a universal and legally binding international climate agreement, to be adopted, if all goes to plan, at COP21 in Paris in December 2015.

The Lima meeting comes on the heels of the release of the IPCC's latest Synthesis Report, which was agreed in Copenhagen in late October. Hailed as the "most comprehensive assessment of climate change yet undertaken" it contains few surprises. What it does do though is to make clear that the evidence for climate change is now unequivocal, with observed changes that are "unprecedented over decades to millennia". No serious person questions the reality of natural variability in the Earth's climate system. Such variability is caused by known internal drivers and by temporal changes in the amount of solar radiation reaching the Earth's surface. But the dominant causes of global warming since pre-industrial times are, as the report's authors put it, "extremely likely" to be emissions of greenhouse gases - notably carbon dioxide, methane and nitrous oxide and other anthropogenic drivers such as landuse change. As the report also makes patently clear, many human and natural systems have proved to be highly sensitive to climate change, which is already having widespread impacts in many realms, on continents, the Arctic, and the oceans.

Cumulative emissions of greenhouse gases make it almost certain that we are already committed to further warming in the near future. Without deep cuts in emissions over the next couple of decades and the achievement of 'negative emissions' (for example through carbon capture and storage) after 2050 the odds against keeping global warming in check seem long. This has led many researchers to contemplate a world in which global mean temperatures will rise well beyond the $2{ }^{\circ} \mathrm{C}$ target.

But it is not only researchers who are expressing concern - the message that climate change is real, potentially dangerous, and largely caused by the activities of humankind has struck home in civil society.
Witness the hundreds of thousands of concerned citizens that took to the streets of New York during the UN Climate Summit in September this year. And then on 2 October, the United Nations' International Day for Non-Violence (www.un.org/en/events/ nonviolenceday), activists in the Philippines started their approximately 1,000 kilometre 'Climate Walk', from Rizal Park in Luneta, Manila Bay, to Tacloban City, which was devastated by super typhoon Yolanda/Haiyan on 8 November 2013. Along the way, the walkers raised awareness about the need for climate justice. Similar climate-related events, some large some small, have recently been held in about 150 countries. It is hard to dismiss the fact that ordinary citizens around the world are increasingly calling for indeed demanding - meaningful action on climate change and its impacts from their political leaders.

But there are signs that the political tide is turning. A major aim of the New York summit was to "catalyse action on the ground to reduce emissions and build resilience to the adverse impacts of climate change", while helping to eradicate poverty and promote sustainability. With these aims in mind, the leaders of several countries along with representatives from cities and corporations pledged action on emissions, with the collective aim of achieving a 'zero carbon' or 'emissions neutral' world economy by around mid-century. Countries of the European Union have announced their intention that by 2030 emissions will be reduced to at least $40 \%$ below what they were in 1990 .

And then in November, following talks in Beijing, President Obama announced the goal of cutting US greenhouse-gas emissions by $26-28 \%$ below 2005 levels by 2025, while President Xi pledged that China's carbon dioxide emissions would peak by 2030, in part through greater use of non-fossil fuels for energy. If fulfilled, these pledges from the world's two great superpowers will come to be seen as historic.

Meanwhile, climate finance has come to the fore - including issues around carbon markets and financial transfers. There is also the question of how climate funds should be financed and administered. Increasing numbers of countries have agreed to help fill the coffers of the Green Climate Fund (Nature Clim. Change 4, 953; 2014). One of the first countries to do so was Germany, which in July this year pledged a contribution of $€ 750$ million to the fund. This courageous initiative from Chancellor Angela Merkel set an early example to other wealthy nations. Despite a degree of foot dragging, the word on the street is that further significant pledges from other countries can be expected soon.

What happens over the next $10-15$ years is critically important if we are to stay on the two-degree path and so avoid the worst impacts of climate change. This is likely to entail a radical transformation of world economies with a burgeoning of low-carbon technologies and infrastructures. Right now it is crucial that climate finance is aimed at mitigation and adaptation measures that are likely to be effective on the ground. It is equally important that money should be redirected away from dirty industries. Subsidies for fossil fuels, for example, far outstrip those for renewables; they should be phased out at the earliest opportunity. Inevitably, all of this invokes nervousness from industrialists who perceive themselves, wrongly, to be potential losers - wrong, that is, if they learn to adapt and future-proof themselves through technological innovation and investment.

In early November this year, the Royal Institute of International Affairs held a conference entitled Climate Change: Raising Ambition, Delivering Results at Chatham House in London. Speaker after speaker, whether from academia, government, policy circles, or industry, spoke of the need to see climate change and climate finance as an opportunity rather than an economic burden. Indeed there is reason to think that economic growth could be a major co-benefit of climate change mitigation and adaptation, if managed in such a way as to increase economic efficiency. One important requirement for this to happen is that policies should be set in the 'real economy', rather than being based, for example, on fanciful notions of the imminent demise of capitalism and globalization.

The critical elements needed for agreement in Paris in December 2015 are probably already well understood - now political resolve is needed to put them in place. As 2014 draws to a close, the Lima meeting represents a chance to help facilitate that process. More importantly, the next $10-15$ years represent a window of opportunity - maybe the only one we will get - to avoid dangerous climate change. 